\title{
Metastasis to left scapula with unknown primary: Approach to pathological diagnosis
}

\author{
Shaista M Vasenwala, Hena A Ansari, Nazima Haider, Amir bin Sabir', Aseeb Ur Rehman
}

\section{Abstract}

Bony metastasis is a frequent occurrence in malignancy. However, the clinical presentation and pathological findings may sometimes be more in favor of a primary bone lesion. In such cases, immunochemistry has a very important role to play in reaching a final diagnosis. We present the case of a 35 year male patient who was investigated for a lytic lesion in the left scapula and was finally diagnosed with metastatic adenocarcinoma with the help of immunostaining.

Key words: Immunohistochemistry, metastasis, scapula, unknown primary

\section{Introduction}

The bony skeleton of the human body is frequently a site for metastatic deposits of malignant cells. Often the patient comes with an initial history of bone pain or a pathological fracture following mild trauma. The clinician is faced with a diagnostic challenge-is the lesion a primary bone disease or is it a metastatic focus? Usually, clinico-radiological correlation and pathological studies help in resolving the problem. However, on occasion, it becomes virtually impossible to differentiate a primary lesion from metastasis and determine the source.

We present the case of a young adult male patient who came with complaint of pain in the left shoulder and was diagnosed as a case of a metastatic adenocarcinoma with unknown primary.

\section{Case Report}

A 35-year male presented in the orthopedics outpatient section with a history of pain and gradually increasing swelling in the left shoulder, since six months. There was history of fever off and on and $10 \%$ weight loss. On examination a firm, tender swelling, $10 \times 8 \mathrm{~cm}$ in size was seen over left scapular region with dilated veins on the surface. Local temperature was not raised. The skin was intact.

The investigations showed hemoglobin $6.8 \mathrm{~g} \%$ and raised total white cell count as 16,200 cells/cu.mm. Differential count showed neutrophils $75 \%$, lymphocytes

Departments of Pathology and 'Orthopedics, Jawaharlal Nehru Medical College, AMU, Aligarh, Uttar Pradesh, India

Correspondence to: Dr. Hena A.Ansari,

E-mail: hena.jnmc@gmail.com

\begin{tabular}{|l|l|}
\hline \multicolumn{2}{|c|}{ Access this article online } \\
\hline Quick Response Code: & Website: \\
\hline
\end{tabular}

$20 \%$, eosinophils $4 \%$ and monocytes $1 \%$. Erythrocyte sedimentation rate was $70 \mathrm{~mm}$ in the first hour. X-ray revealed a large lytic lesion in the left scapula, without soft tissue extension [Figure 1]. The X-ray chest showed hyperinflated lungs and bronchiectatic changes in both lungs. An abdominal ultrasound showed no abnormality.

Fine needle aspiration cytology revealed cells arranged in small groups against a hemorrhagic background. The cells were large, about $60 \mu$, with well-defined borders, abundant dense eosinophilic cytoplasm, pleomorphic nuclei with high $\mathrm{N} / \mathrm{C}$ ratio and prominent nucleoli [Figure 2]. Occasional multinucleated tumor giant cells were also observed. The cytological findings led to a provisional diagnosis of an osteogenic sarcoma, vs. a metastatic adenocarcinoma.

The surgical biopsy specimen consisted of haemorrhagic, creamish-white tissue pieces, of aggregate $2 \mathrm{~cm}$. Formalin fixed Haematoxylin and Eosin stained sections showed round to polyhedral cells arranged in the form of trabeculae, cell balls and pseudoglands separated by fine vascularized septa [Figure 3]. The nuclei were pleomorphic with large nucleoli and intranuclear inclusions. The

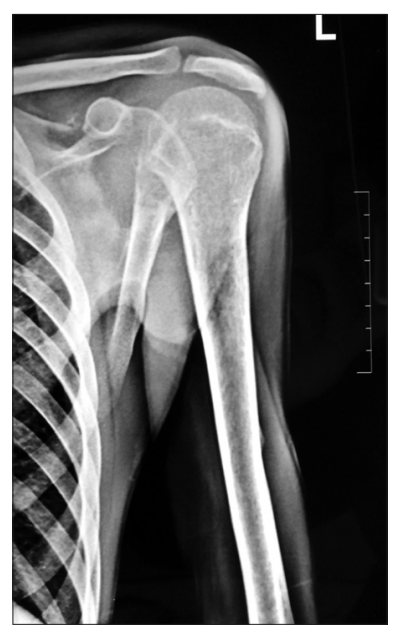

Figure 1: Radiograph of left scapula and shoulder region showing a well-defined lytic zone, without involvement of soft tissue 
cytoplasm was eosinophilic, granular and finely vacuolated. Mitotic activity was low (1-2/10 hpf).

The impression was that of a malignant paraganglioma with the differential diagnosis of metastatic adenocarcinoma,. A Periodic acid Schiff (PAS) stain was carried out and additional immunostaining for Chromogranin, Synaptophysin, S-100 protein, AE-1/AE-3, and Cytokeratins (CK) 7 and 20 was performed.

The results were very interesting. The PAS stain was weakly positive in some cells in the cytoplasm and also in lumina. The Chromogranin, Synaptophysin and S-100 stains were negative. The AE-1/AE-3 and CK-7 stains were strongly positive, while CK-20 was negative [Figures 4a,b].

The final diagnosis was that of a metastatic adenocarcinoma, probably arising from the lungs.

\section{Discussion}

The cell morphology in this case presented a challenging diagnostic dilemma. The clinicoradiologic profile and

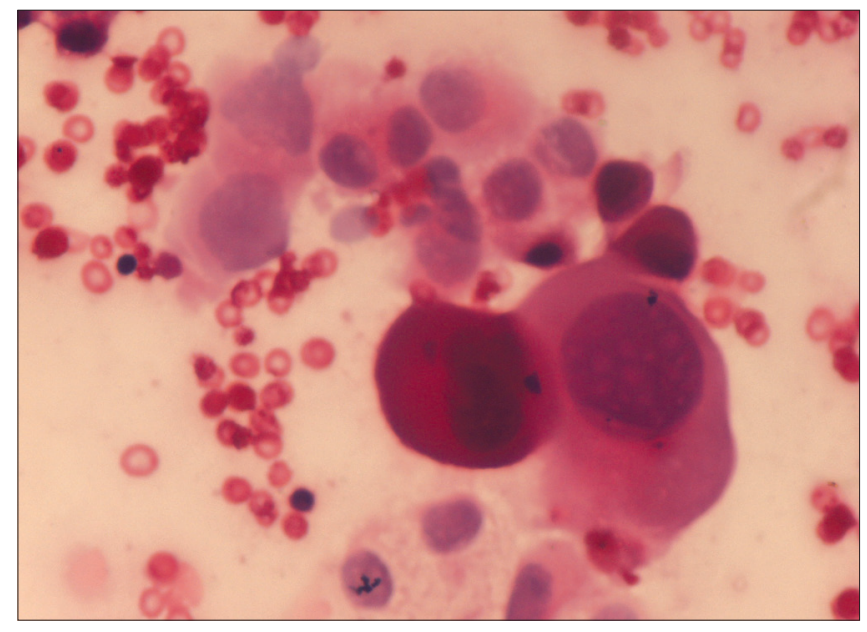

Figure 2: FNAC smear showing small groups of malignant cells with well-defined cell borders, dense eosinophilic cytoplasm, high N/C ratio, nuclear pleomorphism and nucleoli $(H$ and $E, \times 500)$ cytological findings suggested a possible primary bony malignancy. The histological picture was in the favor of a metastatic lesion, either a malignant paraganglioma or an adenocarcinoma. The cytokeratin staining pattern of positive AE1/AE-3 and CK 7 clinched the diagnosis of metastatic adenocarcinoma probably from lung. The negative CK 20 ruled out the possibility of adenocarcinoma arising from stomach and colon.

Solitary lytic lesions in bone are often detected on imaging studies following investigations for persistent bony pain or pathological fractures. The incidence of secondary solitary bone involvement in malignancies has been reported to be around $64 \% .^{[1]}$ Majority of the cases are seen in breast, lung, thyroid, prostate and renal cancers and most lesions involve the axial skeleton. ${ }^{[2]}$ Solitary metastasis occurs most often in the spinal vertebrae. ${ }^{[3]}$ Patients with metastatic bone disease usually present with bone pain, or fractures, especially in lytic lesions. Other features include arthritic features, gout, or rheumatic complaints. ${ }^{[3]}$

On radiography, lung, renal and thyroid neoplasms are

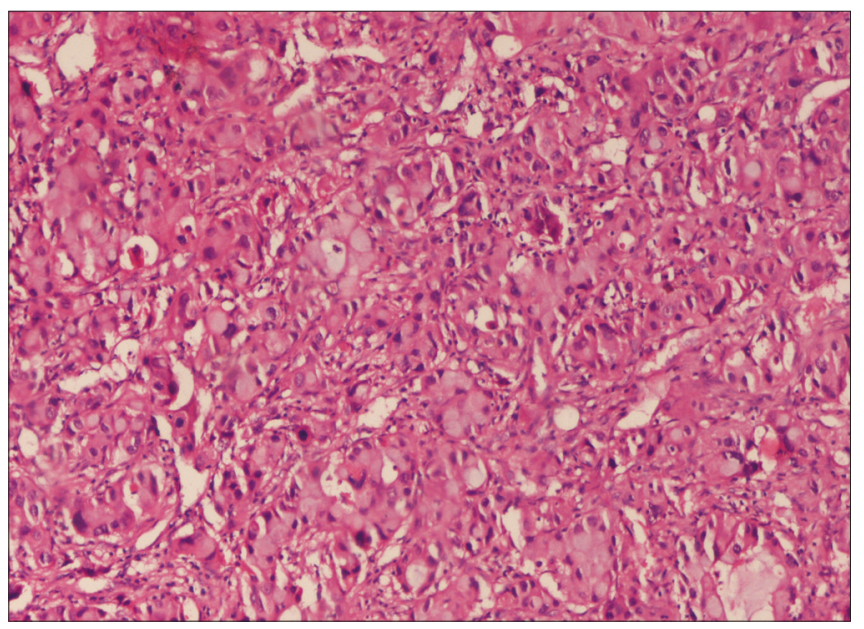

Figure 3: Tissue section showing malignant cells arranged in cell balls and peudoglands, separated by finely vascularized stroma $(H$ and $E, \times 250$ )
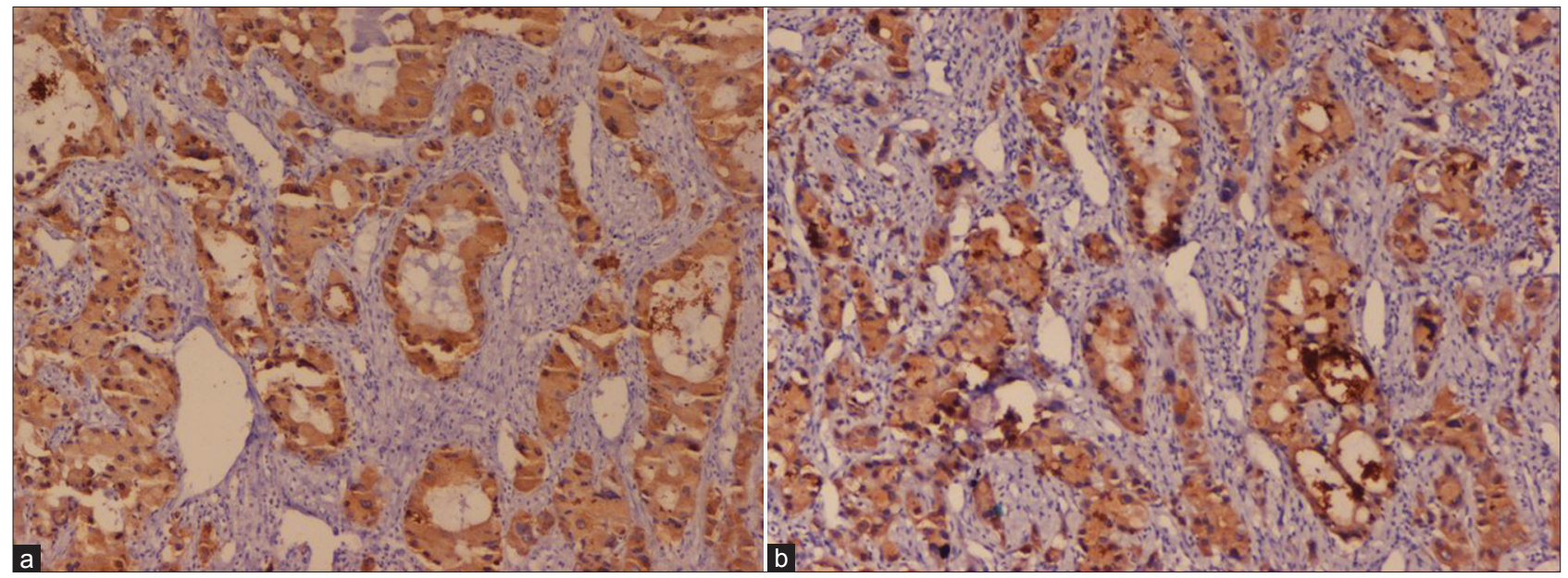

Figure 4: Tissue section showing positive immunostaining for AE-1/AE-3 (a) and CK 7 (b) (x125) 
usually lytic, while, prostate and breast cancer can cause sclerosis. ${ }^{[3]}$ A destructive bony lesion with irregular borders and/or soft tissue involvement should raise suspicion of a malignant process.

Our patient was a young male and did not present with any symptoms which would indicate a pulmonary or gastrointestinal malignancy. There were no palpable lymphnodes. The thyroid gland was not enlarged and ultrasonography did not detect any suspicious lesion in the kidney. Prostatic cancer also excluded as there were no suggestive clinical findings and the age of the patient was also not in favor of a prostatic tumor. Before doing the tumor marker studies, primary bone tumor was the provisional diagnosis. A careful clonical workup is essential. In addition, the levels of certain tumour markers may be analysed, such as Carcinoembryonic antigen (CEA) and prostate specific antigen (PSA). Theses are helpful both in diagnosis as well as followup.

Pathological features are usually indicative of the primary cancer, especially in squamous and adenocarcinomas of the lung, gastrointestinal and ovarian malignancies, thyroid and renal cancers. However, immunochemistry is very helpful in such cases. Studies have shown that adenocarcinomas of lung, ovary, uterus, breast, thyroid, gall bladder and salivary gland usually show a CK $7+$ / CK 20- profile, while colonic adenocarcinoma, and Merkel cell carcinoma, are usually CK 7-/CK $20+.^{[4-11]}$ Adrenal cortical carcinomas, prostatic carcinoma, thymomas and hepatocellular carcinomas how a CK7-/CK20- staining reaction. ${ }^{[4]}$ The combination of $\mathrm{CK} 7$ and 20 is thus useful in differentiating large intestine adenocarcinoma from adenocarcinoma of lung, breast or ovary. ${ }^{[4]}$ It is important to remember that the cytokeratin staining pattern may be altered in metastatic deposits as compared to the primary tumor. ${ }^{[12]}$ In addition, rectal carcinomas often show CK 7 +/CK 20- pattern of staining. ${ }^{[13]}$ Therefore, the immunohistochemical profile is to be interpreted in conjunction with the clinicoradiologic findings.

Regarding the other histological differential diagnosis, malignant paragangliomas often show reduced staining for neuroendocrine markers and S-100 protein. ${ }^{[14-16]}$ Paragngliomas are also cytokeratin-negative, ${ }^{[17]}$ which was not the picture in our case. Interestingly, paragangliomas of the cauda equina are focally cytokeratin positive. ${ }^{[18]}$

In conclusion, we wish to emphasize the importance of clinic-radiologic and pathological correlation in reaching a final diagnosis, as highlighted by the case under studyespecially the contribution of Immunohistochemistry.

\section{References}

1. Corcoran RJ, Thrall JH, Kyle RW, Kaminski RJ, Johnson MC. Solitary abnormalities in bone scans of patients with extraosseous malignancies. Radiology 1976; 121:663-7.

2. Rosai J, editor. Rosai and Ackerman's surgical pathology. $10^{\text {th }}$ ed. Edinburgh: Elsevier Mosby; 2011. p. 2013-4.

3. Rybak LD, Rosenthal DI. Radiological imaging for the diagnosis of bone metastases. Q J Nucl Med 2001;45:53-64.

4. Chu P, Wu E, Weiss LM. Cytokeratin 7 and Cytokeratin 20 expression in epithelial neoplasms: A Survey of 435 Cases. Mod Pathol 2000; 13:962-72.

5. Wang NP, Zee S, Zarbo RJ, Bacchi CE, Gown AM. Coordinate expression of cytokeratins 7 and 20 defines unique subsets of carcinomas. Appl Immunohistochem 1995;3:99-107.

6. Kummar S, Fogarasi M, Canova A, Mota A, Ciesielski T. Cytokeratin 7 and 20 staining for the diagnosis of lung and colorectal adenocarcinoma. Br J Cancer 2002;86: 1884-7.

7. Loy TS, Calaluce RD. Utility of cytokeratin immunostaining in separating pulmonary adenocarcinomas from colonic adenocarcinomas. Am J Clin Pathol 1994; 102:764-7.

8. Loy TS, Calaluce RD, Keeney GL. Cytokeratin immunostaining in differentiating primary ovarian carcinoma from metastatic colonic adenocarcinoma. Mod Pathol 1996;9:1040-4

9. Kaufmann O, Deidesheimer T, Muehlenberg M, Deicke P, Dietel M. Immunohistochemical differentiation of metastatic breast carcinomas from metastatic adenocarcinomas of other common primary sites. Histopathology 1996;29:233-40.

10. Maeda T, Adachi E, Kajiyama K, Sugimachi K, Tsuneyishi M. Combined hepatocellular and cholangiocarcinoma: Proposed criteria according to cytokeratin expression and analysis of clinicopathologic features. Hum Pathol 1995;26:956-64.

11. Zemer R, Fishman A, Bernheim J, Zimlichman S, Markowicz O, Altaras M, et al. Expression of cytokeratin-20 in endometrial carcinoma. Gynecol Oncol 1998;70:410-3.

12. Tot T. Cytokeratins 20 and 7 as biomarkers: Usefulness in discriminating primary from metastatic adenocarcinoma. Eur J Cancer 2002;38:758-63.

13. Bayrak R, Yenidünya $\mathrm{S}$, Haltas $\mathrm{H}$. Cytokeratin 7 and cytokeratin 20 expression in colorectal adenocarcinomas. Pathol Res Pract 2011;207:156-60.

14. Linnoila RJ, Lack EE, Steinberg SM, Keiser HR. Decreased expression of neuropeptides in malignant paragangliomas. An immunohistochem study. Hum Pathol 1988; 19:41-50.

15. Achilles E, Padberg BC, Holl K, Kloppel G, Schroder S. Immunocytochemistry of paragangliomas - value of staining for S-100 protein and glial fibrillary acidic protein in diagnosis and prognosis. Histopathology 1991;18:453-8.

16. Kliewer KE, Wen DR, Cancilla PA, Cochran AJ. Paragangliomas: Assessment of prognosis by histologic, immunohistochemical, and ultrastructural techniques. Hum Pathol 1989;20:29-39.

17. Moran CA, Rush W, Mena H. Primary spinal paragangliomas: A clinicopathological and immunohistochemical study of 30 cases. Histopathology 1997;31:167-73.

18. Labrousse F, Leboutet MJ, Petit B, Paraf F, Boncoeur-Martel MP, Moreau JJ, et al. Cytokeratins expression in paragangliomas of the cauda equine. Clin Neuropathol 1999;18:208-13.

How to cite this article: Vasenwala SM, Ansari HA, Haider N, Sabir Ab, Ur Rehman A. Metastasis to left scapula with unknown primary: Approach to pathological diagnosis. South Asian J Cancer 2013;2:2.

Source of Support: Nil. Conflict of Interest: None declared. 